九州大学学術情報リポジトリ

Kyushu University Institutional Repository

\title{
A new approach for evaluating crack growth resistance curve of mode II delamination by doubly end-notched tension tests
}

Yashiro, Shigeki

Department of Aeronautics and Astronautics, Kyushu University

Agata, Toshihide

Graduate School of Integrated Science and Technology, Shizuoka University

Yoshimura, Akinori

Aeronautical Technology Directorate, Japan Aerospace Exploration Agency (JAXA)

http://hdl. hand le. net/2324/4476074

出版情報: Advanced Composite Materials. 27 (2)，pp.119-133，2017-09-08. Taylor and Francis バージョン：

権利関係 : 


\title{
A new approach for evaluating crack growth resistance curve of mode II delamination by doubly end-notched tension tests
}

Shigeki Yashiro ${ }^{1, *}$, Toshihide Agata ${ }^{2, a}$, Akinori Yoshimura ${ }^{3}$

${ }^{1}$ Department of Aeronautics and Astronautics, Kyushu University

744 Motooka, Nishi-ku, Fukuoka 819-0395, Japan

${ }^{2}$ Graduate School of Integrated Science and Technology, Shizuoka University

Johoku, Naka-ku, Hamamatsu 432-8561, Japan

${ }^{3}$ Aeronautical Technology Directorate, Japan Aerospace Exploration Agency (JAXA)

6-13-1, Osawa, Mitaka, Tokyo 181-0015, Japan

${ }^{\text {a }}$ Current address: Toyota Industries Corporation

* Corresponding author: yashiro@aero.kyushu-u.ac.jp (S. Yashiro)

\begin{abstract}
Quantitative determination of interlaminar fracture toughness that governs onset and growth of delamination is essential for engineering of composite materials and structures. This study proposes a new approach to evaluate both the initial fracture toughness and the crack growth resistance property of pure mode II delamination by tensile tests of specimens having two initial cracks, which were conceived from double-lap joints. The proposed test method achieves stable growth of mode II delamination by using a fundamental testing system. This study presents the specimen configuration, the theory to evaluate the energy release rate, and experiment results. The mode II initial fracture toughness measured by the present approach agreed well with the
\end{abstract}


results of conventional end notched flexure tests. Furthermore, the crack growth resistance curves were evaluated by unloading-reloading tests of the proposed doubly end-notched tension specimens.

Keywords: Polymer-matrix composites (PMCs); Delamination; Fracture toughness; Mechanical testing.

\section{Introduction}

Carbon fiber reinforced plastics (CFRPs) have been frequently used in primary structures of the latest airplanes because of their high specific strength and modulus as well as good fatigue properties. Use of CFRPs are now growing rapidly in various industries. CFRPs are often used as a laminate in which thin layers are stacked, but in general, delamination appears frequently because of the inevitable interlaminar shear stress and the lack of through-thickness reinforcement. Delamination significantly degrades compressive strength [1]. Therefore, quantitative evaluation of delamination onset and its growth is important.

Standardization of test methods for interlaminar fracture toughness has been investigated [2]. Mode I interlaminar fracture toughness of unidirectional fiber-reinforced polymer matrix composites has been measured by the double cantilever beam (DCB) test, which is prescribed as a standard test method [3-5]. The end notched flexure (ENF) test [6] has been frequently performed to evaluate mode II interlaminar fracture toughness, and this test is prescribed as a standard method in Japanese Industrial Standard (JIS) [3] and ASTM [7]. However, international consensus on standardization of the ENF test has not been reached due to the 
unstable nature of crack growth and the influence of friction [2]. Some test methods have been addressed to achieve stable growth of mode II delamination [8-10]. The stabilized ENF test $[11,12]$ requires a complex testing system for the control of the crack shear displacement or the coordinate conversion control. The end loaded split (ELS) test $[13,14]$ requires a special horizontally-sliding clamp. The four-point bend ENF test $[15,16]$ has to take into account the friction, because the loading point is above the initial delamination. Friction is also assumed in the over notched flexure (ONF) test [10]. Therefore, the influence of friction on the apparent fracture toughness has been investigated [10,17-20]. In recent years, new methods have been developed to obtain the crack growth resistance curve (R-curve) of mode II delamination. Arrese et al. [21] obtained the mode II R-curve by the three-point ENF test based on a set of equations of the compliance and the energy release rate considering shear, local deformation and bending rotation effects. Nakatani et al. [22] obtained an analogical R-curve of mode II delamination by tensile tests of unidirectional CFRPs containing designed discontinuity of fibers, but some specimens are required to evaluate the R-curve due to unstable failure manner. The mixed mode bending (MMB) test $[23,24]$ and the cracked lap shear (CLS) test $[25,26]$ to evaluate mixed mode I and II fracture toughness are well-known, but test methods for mixedmode delamination growth are still of interest [27-29].

This study proposes a new approach to achieve stable growth of mode II delamination by using a simple testing system and presents a theory to evaluate the energy release rate. We focused on the crack growth in a double-lap joint. Cracks between the base plate and lap plates are ideally in pure mode II. The influence of friction is small because of the absence of external 
forces in the through-thickness direction. This study will evaluate both the initial fracture toughness and the R-curve of mode II delamination by the newly proposed doubly end-notched tension (DENT) tests.

This paper is organized as follows. Section 2 proposes the DENT specimen that idealizes a half of a double-lap joint. A shear-lag analysis to evaluate the energy release rate is also presented. This theory will indicate that the energy release rate is independent of the crack length and that the delamination growth is stable. Finite-element analysis of the proposed test is also performed to confirm the stress distribution predicted by the shear-lag analysis. In Section 3, the proposed DENT test will be verified by comparing the measured initial mode II fracture toughness $G_{\text {IIC }}$ of unidirectional CFRP laminates with that obtained by the conventional ENF test. Furthermore, the fracture toughness during delamination growing stage, GIIR (i.e., Rcurve), will be evaluated by unloading-reloading tests.

\section{Evaluation of mode II energy release rate by doubly end-notched tension tests}

This study proposes the DENT specimen conceived from a double-lap joint, and Fig. 1a depicts the configuration of the proposed specimen. The two plates at the left end are the lap plates, and the region within $x \geq-a$ corresponds to the bonded area. Two initial cracks (length a) are introduced from the end of the overwrap. Growth of pure mode II delamination is achieved by applying tensile load to this specimen.

\subsection{Theory}


The stress recovery in the middle layer and the compliance of overall specimen can be obtained by a shear-lag analysis [30]. The interlaminar shear stress between the surface layer and the middle layer, $\tau$, is written by

$$
\tau=G \frac{\left(u_{1}-u_{2}\right)}{t}
$$

where $G$ and $t$ are the shear modulus and the thickness of the shear layer; $u_{1}$ and $u_{2}$ are the displacements of the surface and middle layers in the longitudinal $(x)$ direction defined in Fig. 1a. Equilibrium of force in an infinitesimal element in the middle layer (Fig. 1b) provides

$$
\frac{d \sigma_{2}}{d x}=-\frac{2 \tau}{h_{2}}=-\frac{2 G\left(u_{1}-u_{2}\right)}{h_{2} t}
$$

where $\sigma_{2}$ and $h_{2}$ are the stress and the thickness of the middle layer. By differentiating Eq. (2)

with $x$, the following equation is obtained.

$$
\frac{d^{2} \sigma_{2}}{d x^{2}}=-\frac{2 G}{E h_{2} t}\left(\sigma_{1}-\sigma_{2}\right)
$$

Here, $E$ is the Young's modulus in the $x$-direction, and $\sigma_{1}$ is the stress in the surface layer, which is given as follows.

$$
\sigma_{1}=\frac{P}{2 h_{1} B}-\frac{h_{2}}{2 h_{1}} \sigma_{2}
$$

$P$ is the tensile load, $h_{1}$ is the thickness of the surface layer, and $B$ is the specimen width. Equations (3) and (4) provides

$$
\frac{d^{2} \sigma_{2}}{d x^{2}}=\frac{G H}{E h_{1} h_{2} t}\left(\sigma_{2}-\frac{P}{H B}\right)
$$

where $H\left(=2 h_{1}+h_{2}\right)$ is the total thickness of the specimen. The following two boundary conditions are subjected to Eq. (5): (i) $\sigma_{2}=0$ at the tip of the delamination $(x=0)$, and (ii) perfect stress recovery at the end of the specimen $(x=L-a)$, i.e., $\sigma_{2}=\sigma_{1}=P /(H B)$. The stress in the middle layer is then given by 


$$
\begin{gathered}
\sigma_{2}=\frac{P}{H B}\left\{1-\cosh (k x)+\frac{\cosh [k(L-a)]}{\sinh [k(L-a)]} \sinh (k x)\right\} \\
\text { where } k=\sqrt{\frac{G H}{E h_{1} h_{2} t}} .
\end{gathered}
$$

Within the delaminated region $(-a \leq x \leq 0), \sigma_{2}=0$ and $\sigma_{1}=P /\left(2 h_{1} B\right)$ since the two surface layers support the external force. It is noted that the above theory ignores friction between the surface layer and the middle layer in the delaminated region.

The compliance will be derived based on the above theory. The elongation of the surface layer within the delaminated region $(-a \leq x \leq 0), \delta_{1}$, is

$$
\delta_{1}=\frac{\sigma_{1}}{E} a=\frac{P a}{2 h_{1} B E} .
$$

The elongation of the surface layer within the intact region $(x>0), \delta_{2}$, is obtained as follows.

$$
\delta_{2}=\int_{0}^{L-a} \frac{\sigma_{1}}{E} d x=\frac{P(L-a)}{2 h_{1} B E}\left(1-\frac{h_{2}}{H}\right)-\frac{h_{2} P}{2 h_{1} H B E k} \frac{1-\cosh [k(L-a)]}{\sinh [k(L-a)]}
$$

The compliance of the specimen, $C$, is then written by

$$
C=\frac{\delta_{1}+\delta_{2}}{P}=\frac{a}{2 h_{1} B E}+\frac{L-a}{2 h_{1} B E}\left(1-\frac{h_{2}}{H}\right)+\frac{h_{2}}{2 h_{1} H B E k} \tanh \left[\frac{k}{2}(L-a)\right] .
$$

Taking two cracks into account, the energy release rate is then calculated as

$$
G=\frac{P^{2}}{4 B} \frac{d C}{d a}=\frac{h_{2} P^{2}}{8 h_{1} H B^{2} E}\left(1-\frac{1}{2 \cosh ^{2}\left[\frac{k}{2}(L-a)\right]}\right) .
$$

If the crack length $a$ is sufficiently smaller than the gage length $L$ to satisfy the boundary condition (ii), the second term in the bracket of the right-hand-side of Eq. (11) is negligible, since the shear layer thickness $t$ is of the order of $0.1 \mathrm{~mm}$ (described later). In this case, the energy release rate $G$ is independent of the crack length.

$$
G=\frac{h_{2} P^{2}}{8 h_{1} H B^{2} E}
$$

The two cracks in a DENT specimen thus grow stably. The initial fracture toughness $G_{\mathrm{C}}$ is evaluated by detecting the beginning of nonlinearity in the load-displacement curve of quasi- 
static tensile tests, and the fracture toughness in the growing stage, $G_{\mathrm{R}}$, is obtained by the unloading-reloading tests. In the following section, finite-element analysis will reveal that the cracks in a DENT specimen are in pure mode II. Appendix A shows a stability analysis of the crack growth.

\subsection{Validation by finite-element analysis}

Stress distribution in the DENT test analyzed by the above theory was verified by the finiteelement analysis. Figure 2 depicts the two-dimensional finite-element model considering the symmetry in the through-thickness direction; the analysis was linear elastic under the plane strain condition. The model was $160 \mathrm{~mm}$ long, including the grip region of the actual specimen. The thickness of the surface layer and the half thickness of the middle layer were $0.75 \mathrm{~mm}$; the thickness of the model was $1.5 \mathrm{~mm}$. The initial crack length was $25 \mathrm{~mm}$. The model was discretized by eight-node rectangular elements with a constant size; an element was $0.4 \mathrm{~mm}$ long in the $x$-direction and $0.1875 \mathrm{~mm}$ wide in the $y$-direction. There were 10866 nodes and 3180 elements. The initial crack was modeled by double nodes, and double nodes were also arranged on the extended line of the initial crack. Penalty elements were inserted into the interface except for the initial crack region. When the crack surfaces contacted to each other, penalty stiffness was introduced into the contact region. The left end was fixed in the $x$-direction, and a uniform tensile stress was applied to the right end. The transversely isotropic constitutive law was used, and Table 1 lists the material properties used in the analysis.

Figure 3 compares the distribution of the longitudinal stress $\sigma_{x}$ between the shear-lag analysis 
and FEM; stresses along the lines $\pm 0.1875 \mathrm{~mm}$ above the interface are plotted. Stresses of the shear-lag analysis almost overlapped with those of FEM. This result validated the shear-lag analysis presented in the previous section. Figure 4 depicts the stress distribution near the crack tip. The shear stress concentrated at the crack tip, and the thickness of the stress concentrated region, i.e., the shear layer thickness, was approximately $0.1 \mathrm{~mm}$. Since the value of $k(L-a)$ is approximately $10-100$, the assumption that the energy release rate is independent of the crack length, Eq. (12), is valid. The absence of the crack-opening positive $\sigma_{y}$ at the crack tip demonstrated that delamination grows in pure shear mode in the DENT test. It is noted that the crack-closing negative $\sigma_{y}$ appeared locally at the crack tip, and its influence on the apparent fracture toughness will be investigated in our future work.

\section{Experiment}

\subsection{Doubly end-notched tension specimen}

Figure 5 depicts the dimensions of the DENT specimen. The material used was unidirectional CFRP (T700SC/\#2592, Toray Industries). The stacking sequence was $\left[0_{6} / / 0_{12} / / 0_{6}\right]$. In the molding stage, the surface layers (1st-6th plies and 19th-24th plies) were $200 \mathrm{~mm}$ square, and the middle layer (7th-18th plies) was $150 \mathrm{~mm}$ long and $200 \mathrm{~mm}$ wide. A $1.5 \mathrm{~mm}$ thick polytetrafluoroethylene $(\mathrm{PTFE})$ plate was inserted into the space $(50 \mathrm{~mm} \times 200 \mathrm{~mm})$ of the middle layer in the molding stage. Twofold polyimide films $(12.5 \mu \mathrm{m}$ thick) were inserted into the interfaces between the 6th and 7th plies and between the 18th and 19th plies as the initial cracks, and specimens with four initial crack lengths $\left(a_{i n i}=25,35,50\right.$ and $\left.70 \mathrm{~mm}\right)$ were 
fabricated. The stacked prepreg sheets were cured by a hot-press with a vacuum chamber under the condition of $1.3 \mathrm{MPa}$ pressure and $130^{\circ} \mathrm{C}$ temperature for two hours. Coupon specimens were cut out from the fabricated plate, and the fold line of the polyimide films was cut by a knife. The two cracks extended slightly by this preparation. It is noted that $a_{i n i}$ is not the crack length containing the precrack but the film insert length. Finally, a GFRP plate $1.5 \mathrm{~mm}$ thick was inserted and adhered at the end of the specimen, and GFRP tabs were attached to prevent grip failure. To facilitate observation of the cracks by a measuring microscope (total magnification factor of 40X), the edge of the specimen was painted white as depicted in Fig. $5 b$.

Quasi-static tensile tests of unidirectional coupon specimens were performed in advance to obtain the longitudinal Young's modulus that was determined as the initial slope of the stressstrain curve. Ten specimens were tested and the average Young's modulus was 131.5 GPa.

\subsection{Quasi-static tensile tests for $G_{\text {IIC }}$ measurement}

In order to evaluate the initial mode II fracture toughness $G_{\text {IIC }}$, quasi-static tensile tests were performed for the DENT specimens at the crosshead speed of $0.5 \mathrm{~mm} / \mathrm{min}$ using a hydraulic testing machine (VH-5, The Japan Steel Works). Figure 6 depicts the overview of the experiment setup. The tensile load and the crosshead displacement, which was the substitute of the elongation of the gage section, were recorded. The edge of the specimen was observed continuously during the test, and the test was finished when the delamination reached the end of the gage section. 
Figure 7 plots typical load-displacement curves of four $a_{i n i}$ values. Following the procedure of the DCB test, the critical load $P_{C}$ was determined as the minimum value out of the first of 5\% slope change, the maximum load, and the first load drop. It is noted that $P_{C}$ should be the load that induces growth of the cracks, and $P_{C}$ has to be defined carefully for the DENT test. Continuous observation by the microscope as well as the absence of steep load drop after $P_{C}$ in Fig. 7 confirmed stable delamination growth in all cases. The two cracks grew by the gradual increase of the tensile load after $P_{C}$, and the load increase at the final stage in the loaddisplacement curves corresponded to tension after complete delamination in the gage section.

Table 2 lists the initial mode II interlaminar fracture toughness $G_{\text {IIC }}$ calculated by Eq. (12) along with the results of ENF tests for the same material. The fracture toughness values of four initial crack lengths were almost identical, and these values obtained by the present test method agreed well with the ENF test. This result confirmed the validity of the mode II fracture toughness obtained by the DENT tests.

\subsection{Unloading-reloading tests for $G_{\text {IIR }}$ evaluation}

Unloading-reloading tests of the DENT specimens were performed to evaluate the crackgrowth resistance property of the mode II delamination. The crosshead speed was $0.5 \mathrm{~mm} / \mathrm{min}$. The specimens were unloaded at some prescribed crosshead displacements that included the load smaller than the critical load $P_{C}$. The crack length was measured by the measuring microscope during the unloading stage. The unloading process was halted at a small load (1 $\mathrm{kN})$, and the specimen was again loaded in tension. The test was finished when the delamination 
reached the end of the gage section.

Typical load-displacement curve for $a_{i n i}=25 \mathrm{~mm}$ is plotted in Fig. 8; similar curves were measured in the specimens with the other three initial crack lengths. Delamination grew stably in all $a_{i n i}$ values, similarly to the quasi-static tensile tests. Figure 9 compares the compliance predicted by Eq. (10) with the measured one; the average length of the two cracks are also plotted. The rate of change of the analytical compliance that governs the energy release rate (see Eq. (11)) agreed with the measurements. Although the analytical compliance was smaller than the measured values, the difference between the analysis and the measurement decreased with increasing the initial crack length. Since the region governed by the shear-lag analysis became smaller with a longer crack, the difference would be caused by the disregard of the twodimensional stress distribution in the shear-lag analysis. Another possibility of this difference was the use of the crosshead displacement that substituted for the specimen elongation.

The load just before the beginning of unloading was defined as the critical load $P_{R}$ in the crack growing stage, and the mode II interlaminar fracture toughness $G_{\text {IIR }}$ was evaluated. Figure 10 plots the R-curve, i.e., the relationship between $G_{\text {IIR }}$ and the crack extension $\Delta a$. Since the unloading was repeated before reaching the critical load $P_{C}$ of this material, the apparent $G_{\text {IIR }}$ increased rapidly within a small crack growth. The fracture toughness $G_{\text {IIR }}$ increased slightly with increasing $\Delta a$ after reaching the initial value $G_{\text {IIC. }}$ This result suggested the influence of fiber bridging near the crack tip; detailed observation of the crack tips will be performed in our future work.

Appendix B describes a data reduction procedure to evaluate the R-curve by a single tensile 
test without measuring crack length, which will simplify the test method to obtain $G_{\text {IIR. }}$

\section{Conclusions}

This study proposed and demonstrated doubly end-notched tension (DENT) tests that realized growth of pure mode II delamination as observed in a double-lap joint. A corresponding shear-lag analysis was also presented to evaluate the mode II energy release rate. This theory indicated that the energy release rate in the DENT specimen is constant. Therefore, this test method achieved stable growth of the mode II delamination by a simple tensile test, and enabled us to measure the mode II interlaminar fracture toughness in the crack growing stage, i.e., the crack growth resistance curve. The conclusions are summarized below.

1. Two mode II cracks grew stably in the doubly end-notched tension specimens under quasistatic tensile loading with displacement-controlled condition.

2. The initial fracture toughness $G_{\text {IIC }}$ measured by the present method agreed with the result of the conventional ENF test. Almost identical GIIC was obtained by different initial crack lengths. These results confirmed the validity of the DENT test and the corresponding shearlag analysis.

3. The mode II fracture toughness in the crack growing stage, $G_{\text {IIR, }}$ was successfully obtained by unloading-reloading tests.

Influence of friction at the crack tip generated by the local crack closing compressive stress will be investigated in detail in the future work. 


\section{Appendix A. Stability of crack growth}

The stability of crack growth can be judged by the sign of $\mathrm{d} G_{\mathrm{II}} / \mathrm{d} a$. $G_{\mathrm{II}}$ in the DENT test is obtained by the fracture mechanics as in Eq. (11). For the fixed load condition, $\mathrm{d} G_{\mathrm{II}} / \mathrm{d} a$ is

$$
\frac{d G_{I I}}{d a}=\frac{P^{2}}{4 B} \frac{d^{2} C}{d a^{2}}=-\frac{P^{2}}{4 B} \frac{h_{2} k}{4 h_{1} H B E} \operatorname{sech}\left[\frac{k}{2}(L-a)\right] \tanh \left[\frac{k}{2}(L-a)\right] .
$$

The right-hand side is always negative since $(L-a)>0$, and the crack growth is then stable in this case. For the fixed displacement conditions, $G_{\text {II }}$ is expressed by

$$
G_{\mathrm{II}}=\frac{\delta^{2}}{4 B C^{2}} \frac{d C}{d a}
$$

where $\delta$ is the total elongation $\left(\delta_{1}+\delta_{2}\right)$. By differentiation of this expression under constant $\delta$,

$\mathrm{d} G_{\mathrm{II}} / \mathrm{d} a$ is expressed as follows.

$$
\begin{aligned}
& \frac{d G_{\mathrm{II}}}{d a}=\frac{\delta^{2}}{4 B C^{2}}\left\{\frac{d^{2} C}{d a^{2}}-\frac{2}{C}\left(\frac{d C}{d a}\right)^{2}\right\} \\
& =-\frac{\delta^{2}}{4 B C^{2}} \frac{h_{2} k}{4 h_{1} H B E} \frac{\operatorname{sech}^{3}\left[\frac{k}{2}(L-a)\right]\left\{h_{2} \tanh \left[\frac{3 k}{2}(L-a)\right]+k\left(a h_{2}+2 h_{1} L\right) \sinh \left[\frac{k}{2}(L-a)\right]\right\}}{k\left(a h_{2}+2 h_{1} L\right)+h_{2} \tanh \left[\frac{k}{2}(L-a)\right]}
\end{aligned}
$$

This expression is also negative, and the crack growth is therefore stable under the constant elongation condition, which is more common in tensile tests. Equations (13) and (15) ensure the stable delamination growth in the DENT tests.

\section{Appendix B. R-curve evaluation without measuring crack length}

Since a mode II crack is closed, accurate measurement of its length is difficult, and the resulting R-curve will be affected by the measurement error [13]. The R-curve may be evaluated by a quasi-static tensile test of a DENT specimen without measuring the crack length based on 
the estimated crack length concept. The crack length is estimated from the compliance as follows based on Eq. (10) for a large $(L-a)$ value.

$$
a=\frac{1}{h_{2}}\left(2 h_{1} H B E C-2 h_{1} L-\frac{h_{2}}{k}\right)
$$

A single quasi-static tensile test data will provide the relationship between the energy release rate calculated by Eq. (12) and the crack growth estimated by Eq. (16). However, Eq. (16) includes the unknown shear-layer thickness in the parameter $k$. The following data reduction procedure will overcome this obstacle.

1. Determine the critical load $P_{C}$.

2. Assume the crack length at $P_{C}$, which will be about the same as the crack length before loading.

3. Estimate the parameter $k$ by using the compliance at $P_{C}$.

Although the load-displacement curves of the tensile tests (Fig. 7) provided R-curves, the crack extension $\Delta a$ calculated by Eq. (16) was found to be incorrect. The shear-layer thickness $t$ determined by the estimated parameter $k$ was much larger than the total thickness of the specimen. This method thus requires accurate compliance in both the experiment and analysis.

The other simple procedure to estimate the crack length is the use of the linear relationship between the crack length and the compliance. If the grip of a specimen can be made in the same condition, the crack length will be estimated by using a calibration curve measured in advance, which is used as the substitute of Eq. (16).

\section{References}


[1] Suemasu H. Analytical approaches to compression after impact (CAI) behavior of carbon fiber-reinforced composite materials. Adv Compos Mater 2016; 25:1-18.

[2] Brunner AJ, Blackman BRK, Davies P. A status report on delamination resistance testing of polymer-matrix composites. Eng Fract Mech 2008; 75:2779-2794.

[3] Japanese Industrial Standards (JIS). Testing methods for interlaminar fracture toughness of carbon fibre reinforced plastics. JIS K7086; 1993.

[4] ASTM. Standard test method for mode I interlaminar fracture toughness of unidirectional fiber-reinforced polymer matrix composites. ASTM D5528-94a; 1994.

[5] ISO. Fibre-reinforced plastic composites - Determination of mode I interlaminar fracture toughness, $G_{\mathrm{IC}}$, for unidirectionally reinforced materials. ISO 15024; 2001.

[6] Carlsson LA, Gillespie JW, Pipes RB. On the analysis and design of the end notched flexure (ENF) specimen for mode II testing. J Compos Mater 1986; 20:594-604.

[7] ASTM. Standard test method for determination of the mode II interlaminar fracture toughness of unidirectional fiber-reinforced polymer matrix composites. ASTM D7905; 2014.

[8] Davies P, Blackman BRK, Brunner AJ. Standard test methods for delamination resistance of composite materials: current status. Appl Compos Mater 1998; 5:345-364.

[9] Davies P, Sims GD, Blackman BRK, Brunner AJ, Kageyama K, Hojo M, Tanaka K, Murri G, Rousseau C, Gieseke B, Martin RH. Comparison of test configurations for determination of mode II interlaminar fracture toughness results from international collaborative test programme. Plast Rubber Compos 1999; 28:432-437. 
[10]Wang WX, Nakata M, Takao Y, Matsubara T. Experimental investigation on test methods for mode II interlaminar fracture testing of carbon fiber reinforced composites. Compos Part A 2009; 40:1447-1455.

[11]Kageyama K, Kikuchi M, Yanagisawa N. Stabilized end notched flexure test: characterization of mode II interlaminar crack growth. ASTM STP 1991; 1110: 210-225.

[12] Tanaka K, Kageyama K, Hojo M. Prestandardization study on mode II interlaminar fracture toughness test for CFRP in Japan. Composites 1995; 26:257-267.

[13] Wang Y, Williams JG. Corrections for Mode II fracture toughness specimens of composites materials. Compos Sci Technol 1992; 32:251-256.

[14]Blackman BRK, Brunner AJ, Williams JG. Mode II fracture testing of composites: a new look at an old problem. Eng Fract Mech 2006; 73:2443-2455.

[15] Schuecker C, Davidson BD. Evaluation of the accuracy of the four-point bend end-notched flexure test for mode II delamination toughness determination. Compos Sci Technol 2000; 60:2137-2146.

[16]De Morias AB, Pereira AB. Application of the effective crack method to mode I and mode II interlaminar fracture of carbon/epoxy unidirectional laminates. Compos Part A 2007; 38:785-794.

[17]Davidson BD, Sun X. Effects of friction, geometry, and fixture compliance on the perceived toughness from three-and four-point bend end-notched flexure tests. J Reinf Plast Compos 2005; 24:1611-1628.

[18] Sun X, Davidson BD. A direct energy balance approach for determining energy release 
rates in three and four point bend end notched flexure tests. Int J Fract 2005; 135:51-72.

[19] Sun X, Davidson BD. Numerical evaluation of the effects of friction and geometric nonlinearities on the energy release rate in three- and four-point bend end-notched flexure tests. Eng Fract Mech 2006; 73:1343-1361.

[20]Davidson BD, Sun X, Vinciquerra J. Influences of friction, geometric nonlinearities, and fixture compliance on experimentally observed toughnesses from three and four-point bend end-notched flexure tests. J Compos Mater 2007; 41:1177-1196.

[21] Arrese A, Carbajal N, Vargas G, Mujika F. A new method for determining mode II R-curve by the End-Notched Flexure test. Eng Fract Mech 2010; 77:51-70.

[22] Nakatani H, Osaka K. On the measurement of interlaminar fracture toughness $G_{\text {IIR }}$ by using UD-CFRP with fibre discontinuities. Proc. 41th Domestic Symposium on Composite Materials, September 2016 (Kochi, Japan), 2A-04. (in Japanese)

[23]Reeder JR; Crews JH. Mixed-m bending method for delamination testing. AIAA J 1990; 28:1270-1276.

[24]Benzeggagh ML, Kenane M. Measurement of mixed-mode delamination fracture toughness of unidirectional glass/epoxy composites with mixed-mode bending apparatus. Compos Sci Technol 1996; 56:439-449.

[25] Johnson WS. Stress analysis of the cracked-lap-shear specimen: an ASTM round-robin. Journal Test Eval 1987; 15:303-324.

[26]Fernlund G, Papini M, McCammond D, Spelt JK. Fracture load predictions for adhesive joints. Compos Sci Technol 1994; 51:587-600. 
[27] Suemasu H, Kondo A, Gozu K, Aoki Y. Novel test method for mixed mode II and III interlaminar fracture toughness. Adv Compos Mater 2010; 19: 349-361.

[28] Suemasu H, Tanikado Y. Damage growth behavior and interlaminar fracture resistance of CFRP laminates under shear fracture mode. Adv Compos Mater 2015; 24:451-466.

[29] Javidrad F. An investigation into the mixed-mode delamination growth in unidirectional T800/924C laminates. Adv Compos Mater 2016, 25:403-421.

[30]Hull D, Clyne TW. An Introduction to Composite Materials. Cambridge: Cambridge University Press, 1996.

[31] Yashiro S, Ogi K, Yoshimura A, Sakaida Y. Characterization of high-velocity impact damage in CFRP laminates: Part II - prediction by smoothed particle hydrodynamics. Compos Part A 2014; 56:308-318. 
Table 1 Material properties of a CFRP unidirectional lamina [31].

\begin{tabular}{lc}
\hline Longitudinal Young's modulus $E_{1}(\mathrm{GPa})$ & 139 \\
Transverse Young's modulus $E_{2}(\mathrm{GPa})$ & 9.85 \\
In-plane Poisson's ratio $v_{12}$ & 0.25 \\
Out-of-plane Poisson's ratio $v_{23}$ & 0.38 \\
In-plane shear modulus $G_{12}(\mathrm{GPa})$ & 5.25 \\
\hline
\end{tabular}

Table 2 Measured initial mode II fracture toughness $G_{\text {IIC }}\left(\mathrm{kJ} / \mathrm{m}^{2}\right)$.

\begin{tabular}{|c|c|c|c|c|c|}
\hline \multicolumn{6}{|c|}{ Initial crack length $a_{i n i}(\mathrm{~mm})$} \\
\hline Specimen & 25 & 35 & 50 & 70 & \\
\hline$\# 1$ & 1.029 & 1.182 & 1.274 & 0.779 & 1.139 \\
\hline$\# 2$ & 1.170 & 1.221 & 1.380 & 1.271 & 1.101 \\
\hline$\# 3$ & 0.979 & 1.081 & 1.140 & 0.969 & 0.944 \\
\hline Average & 1.059 & 1.161 & 1.265 & 1.006 & 1.061 \\
\hline
\end{tabular}




\section{Figure captions}

Fig. 1 Configuration of the doubly end-notched tension specimen.

Fig. 2 Finite-element model of the DENT specimen. The crack length was $25.2 \mathrm{~mm}$. Half of the specimen was analyzed considering the symmetry in the through-thickness direction.

Fig. 3 Comparison of the stress $\sigma_{x}$ distribution between the shear-lag analysis and the FEM. Stresses along the lines $\pm 0.1875 \mathrm{~mm}$ above the interface were plotted for FEM.

Fig. 4 Stress distribution near the crack tip.

Fig. 5 Dimensions of the DENT specimen.

Fig. 6 Overview of the experiment setup.

Fig. 7 Load-displacement curves of the quasi-tensile tests for the DENT specimens with four crack lengths.

Fig. 8 Load-displacement curve of the unloading-reloading test for the DENT specimen with $25 \mathrm{~mm}$ initial crack length.

Fig. 9 Change of the crack length and compliance against the elongation. The dotted line and the dashed line represent the lengths of the two cracks, and average length is plotted by the solid line.

Fig. 10 Crack growth resistance curve obtained by the unloading-reloading tests for the DENT specimens with four crack lengths. 


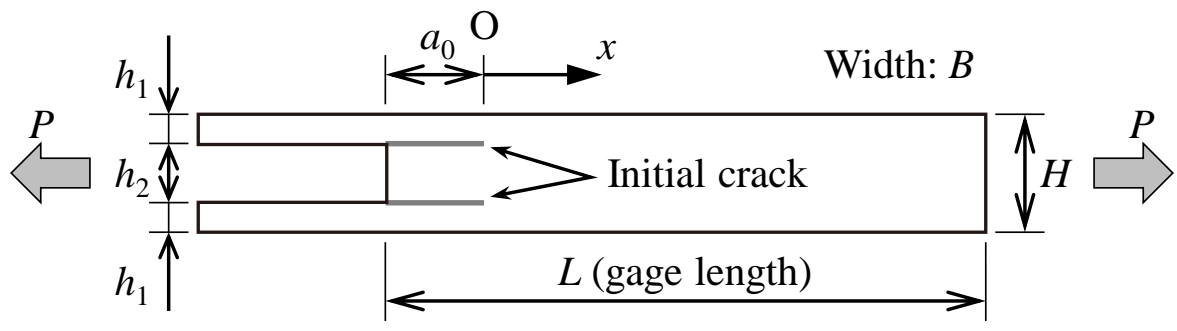

(a) Schematic illustration

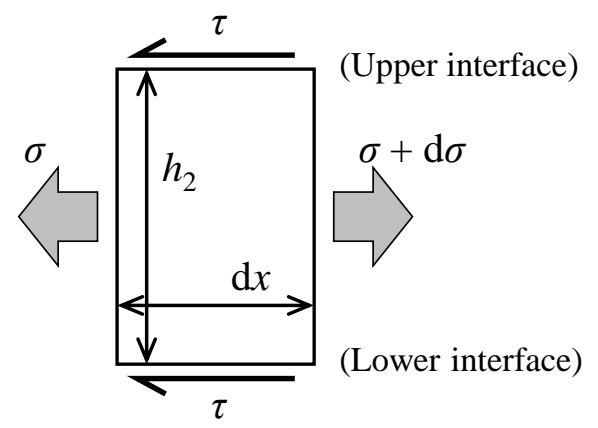

(b) Infinitesimal element in the middle layer

Fig. 1 


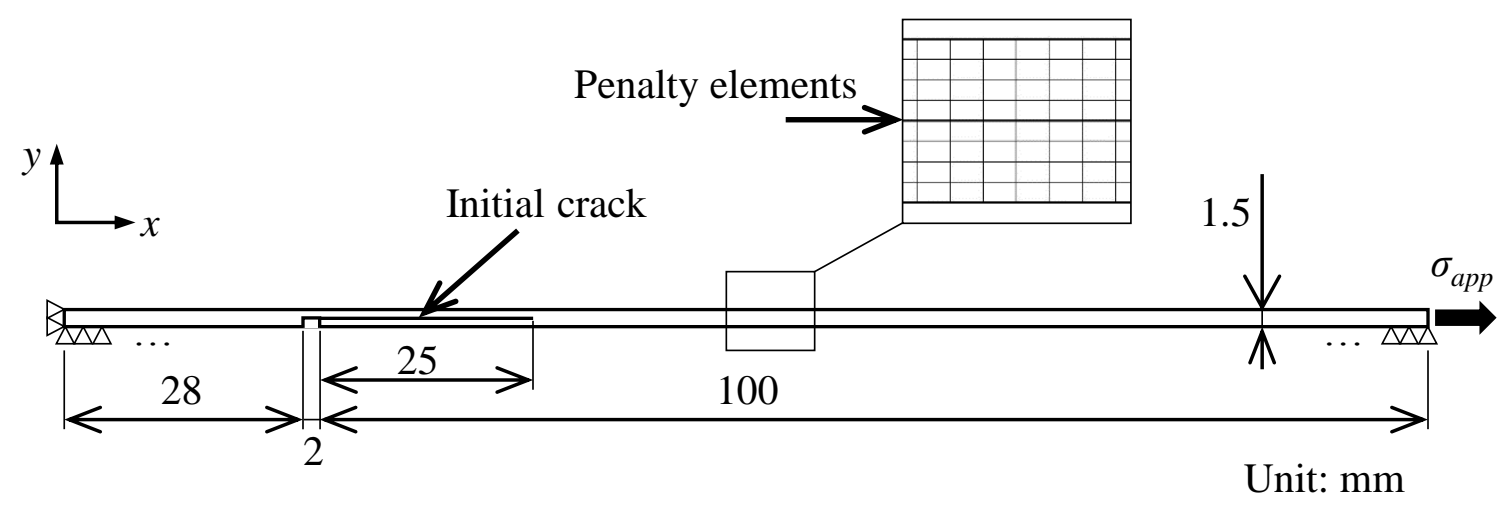

Fig. 2 


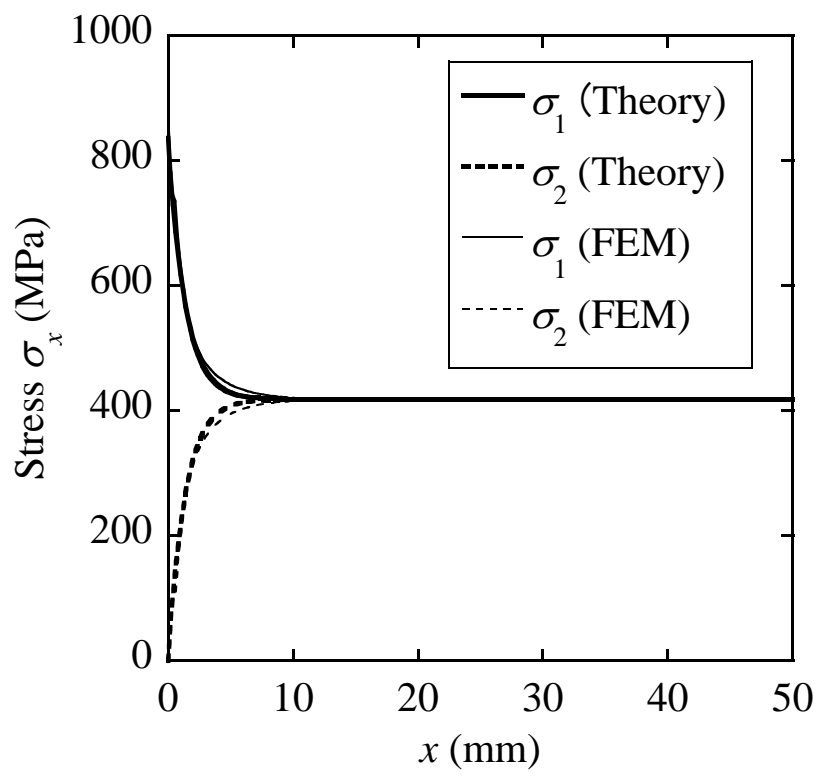

Fig. 3 


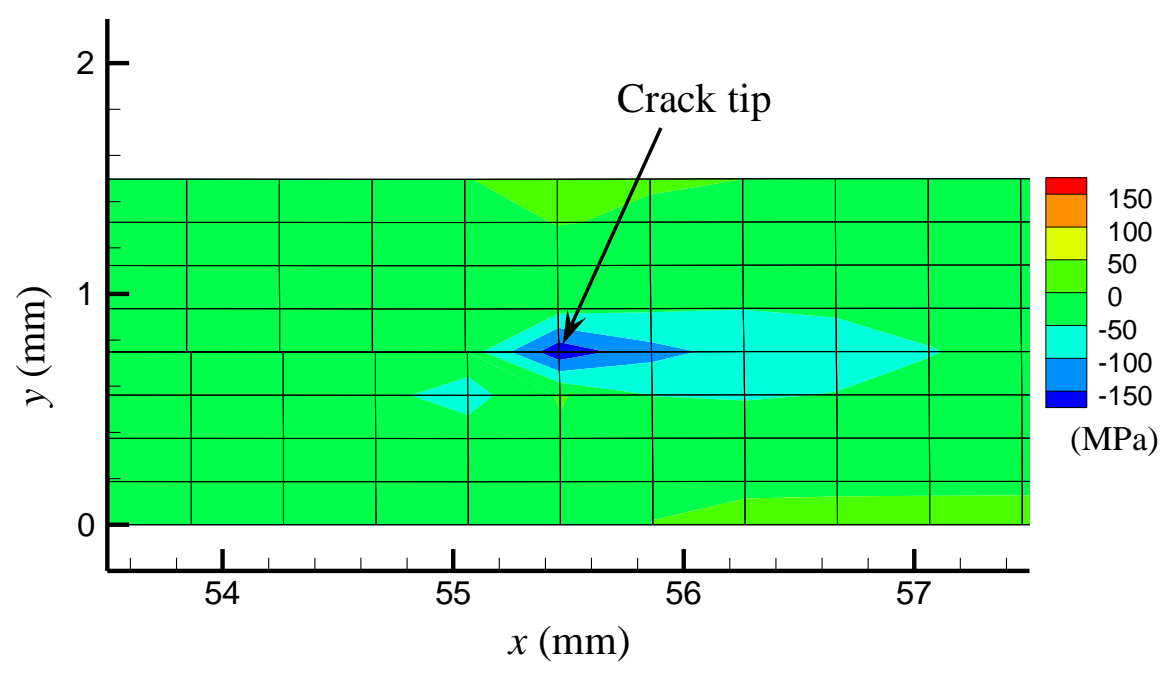

(a) $\tau_{x y}$

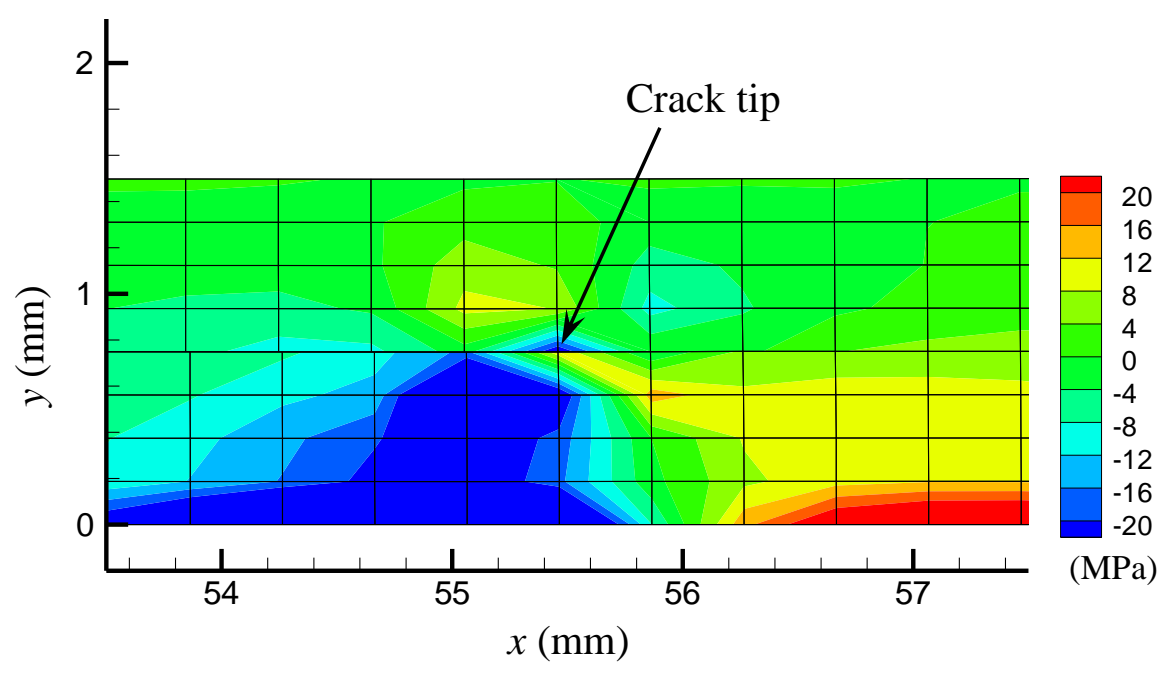

(b) $\sigma_{y}$

Fig. 4 


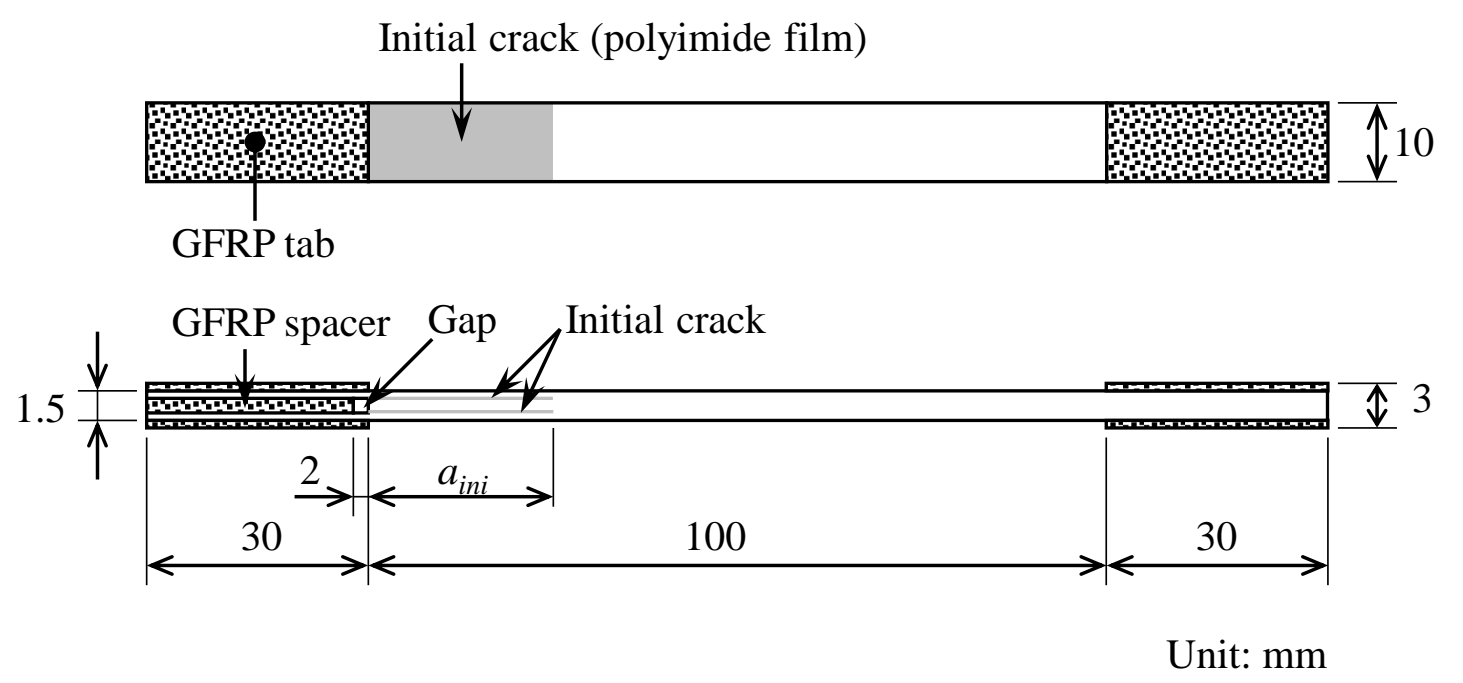

(a) Dimensions

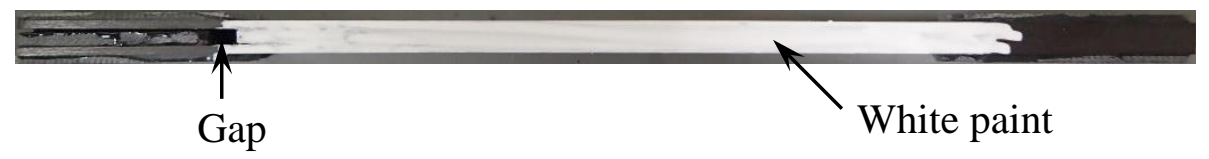

(b) Overview

Fig. 5 


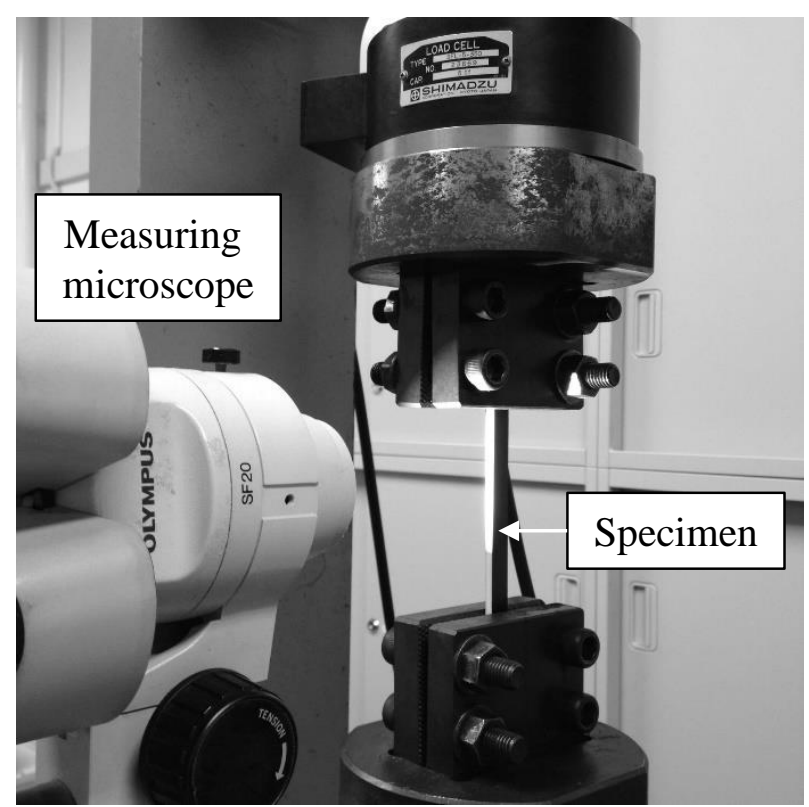

Fig. 6 


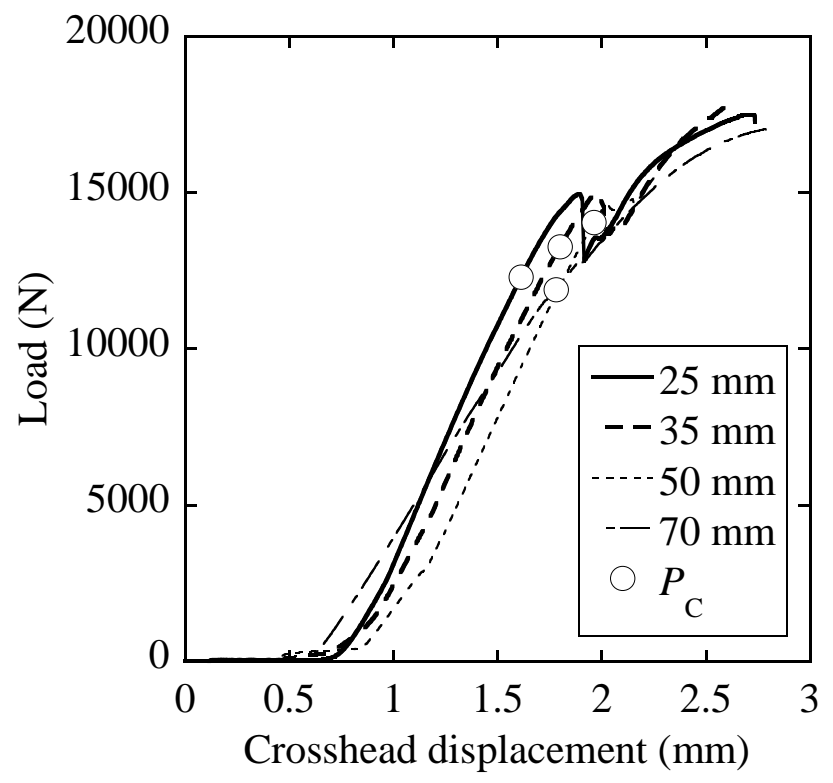

Fig. 7 


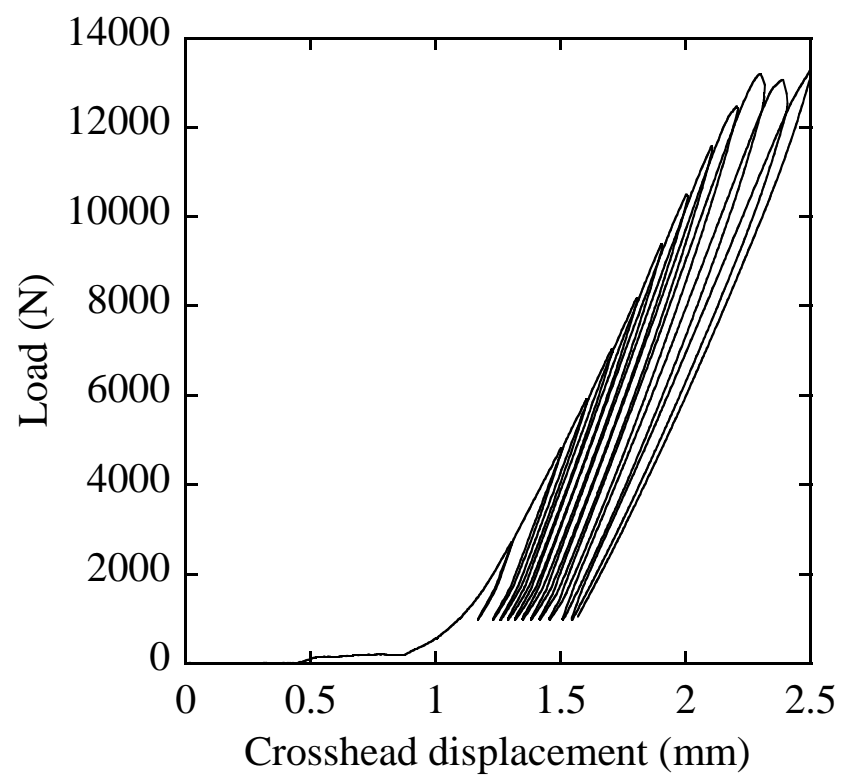

Fig. 8 


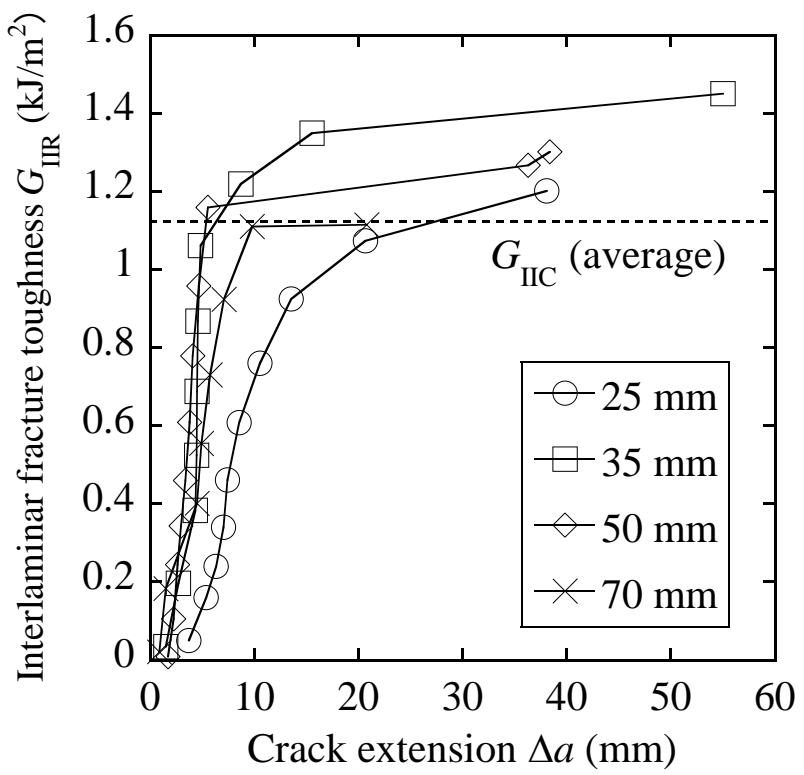

Fig. 10 